\title{
Evaluation of the Impact of Storage Systems on Grid Electricity Demand in the German Context
}

\author{
Dennis Metz \\ PDSSE Program, FEUP/MIT PhD Program \\ Faculdade de Engenharia da Universidade do Porto \\ Rua Dr. Roberto Frias, 4200 - 465 Porto \\ Porto, Portugal \\ dennis.metz@fe.up.pt
}

\author{
João Tomé Saraiva \\ INESC TEC / DEEC \\ Faculdade de Engenharia da Universidade do Porto \\ Rua Dr. Roberto Frias, 4200 - 465 Porto \\ Porto, Portugal \\ jsaraiva@fe.up.pt
}

\begin{abstract}
This paper analyzes the impact of storage installations on grid electricity demand. Storage systems allow the decoupling of consumption from electricity generation and therefore have the potential to change the daily demand profile seen by the network in a significant way. This has far reaching consequences for many stakeholders, as changes in the net demand would for example impact electricity prices or change the requirements for peak generation. The developed approach considers the installation of storage devices to increase selfconsumption of locally generated electricity in a residential and small commercial end users context as well as its application for electricity arbitrage. Assumptions about their implementation on a system level are described and their impact on overall electricity demand is determined considering the German case.
\end{abstract}

Index Terms-Storage, Demand, Electricity Markets

\section{INTRODUCTION}

In the last few decades the generation mix of several countries changed considerably with the strong rise of the share of installations using renewable sources as wind and solar. As an example, in $201427.3 \%$ of the German demand was supplied by renewable units [1]. The volatility of the primary resource used by some of these units places new challenges on the operation of power systems. On the other hand, small- to medium sized storage technologies advanced considerably in recent years. In addition, economies of scale in their production as well as increasing competition among manufacturers have started a price decline, making potential applications also interesting from an economic perspective. Future energy systems will therefore include an increasing number of storage installations, which will have an impact on the demand profile.

One of the potential applications for storage systems is arbitrage of electricity prices, benefitting from the price differentials between valley and peak-demand hours. While this strategy has been exploited by pumped-hydro storage for many years, additional capacity has been difficult to be installed due to geographic requirements and rejection by residents and environmentalists. On the contrary, small- to medium scaled storage systems (such as battery based installations) can be easily deployed.

Another potential application for storage systems is the time-shifting of locally generated electricity for later selfconsumption. Rising electricity prices, among others due to the redistribution of cost associated with the subsidies paid to renewable generation in several countries, makes local electricity generation for self-consumption an attractive alternative. Photovoltaic (PV) installations are especially popular, as they can easily be integrated in existing buildings. Storage systems allow consumers to further reduce their grid electricity demand, as excess generation can be stored for consumption when no local generation is available.

To estimate the potential impact of storage installations for time-shifting of locally generated electricity on grid electricity demand, the generation of PV units and the operation of storage equipment was simulated to satisfy local demand. The modified demand then serves as basis for the decision making process regarding the use of arbitrage by market agents. Last, the combined effect on grid-demand is analyzed.

After this introduction, Section II provides an overview on recent related work in this area. Section III describes the approach which was developed. Obtained results are presented in Section IV. Finally, Section V provides the most relevant findings and discusses remaining questions.

\section{RECENT DEVELOPMENTS REGARDING THE USE OF STORAGE EQUIPMENTS IN ELECTRICITY SYSTEMS}

Publications [2], [3] provide an overview over the most relevant storage technologies as well as discuss their characteristics and technological maturity. Lithium-ion based battery systems seem to be a well suited technology both for installations in residential and small commercial settings as well as for installations pursuing arbitrage.

A growing number of studies is looking at storage installations at the consumer side [4]-[6] or in islandic networks [7]. Most authors find the application of storage devices for time-shifting of locally generated energy marginally profitable today, and expect an increase in their economic attractiveness admitting that electricity rates will increase and installation costs will decline.

Hollinger et al. [8] analyzed the impact of small storage systems on grid demand. They found that the addition of a storage system to a PV installation can relief distribution grids and lead to a steadier residual load, as the maximum feed-in power during midday as well as peak grid demand during evening are both reduced, if the operation algorithm is 
adequately optimized. Büdenbender et al. [9] report that storage systems can effectively level out peaks.

Steffen [10] looked at the prospects for pumped-hydro storage in Germany. He found that arbitrage could be performed in the German electricity market but its profitability strongly depends on the price spread between peak and off peak hours. Kondziella and Bruckner [11] analyzed the potential impact of storage installations pursuing arbitrage on the German electricity market. They identified a reduction in the daily range between minimum and maximum load, and a general smoothing of the load curve.

\section{DEVELOPPED APPROACH}

The following section presents the developed approach. First, storage operations to increase self-consumption of locally generated electricity are introduced and the assumptions detailed. Thereafter, the developed approach for storage systems pursuing energy arbitrage is discussed.

\section{A. Storage for self-consumption}

Electricity demand by individual agents is characterized according to standard load profiles specified by the German Federal Association of the Energy and Water Industry [12]. These profiles reflect the typical electric load patterns for different consumer groups. Figure 1 shows the residential and commercial load profiles.

Residential Load Profile [W] Commercial Load Profile [W]

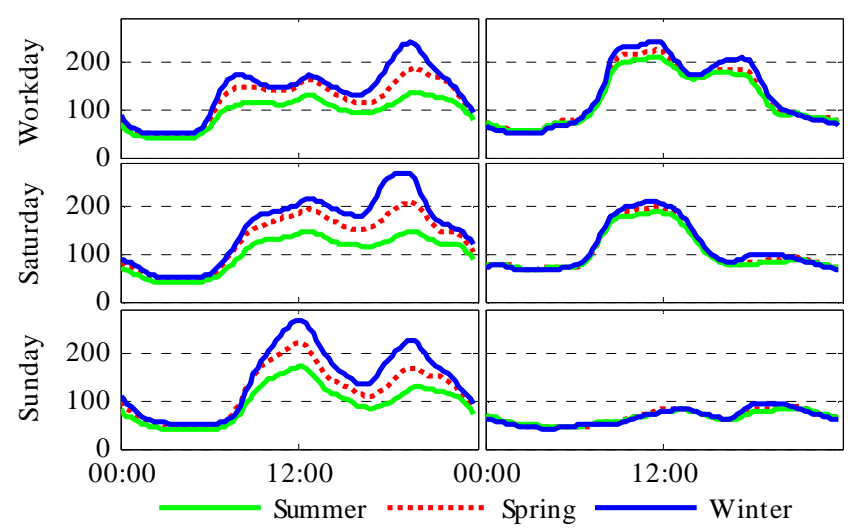

Figure 1: Standard Load Profiles for residential and commercial consumers (for $1 \mathrm{MWh}$ annual demand).

Total electricity demand of residential consumers is almost unchanged between different days, with a distinct peak at about $6 \mathrm{pm}$. On Sundays, there is an additional peak around noon time. Demand during winter exceeds summer-demand by more than $40 \%$. Commercial consumption differs widely between the different days of the week with demand during Sundays almost $50 \%$ lower than during a workday. In this case, the difference between seasons is minimal.

Local generation is assumed to be provided by photovoltaic systems, as they can be easily integrated in existing buildings and do not have any further prerequisite. Expected annual generation is $913 \mathrm{kWh}$ per $\mathrm{kW}$ of installed capacity, and it exhibits a strong seasonal variability [13].
To account for differing installation sizes, several system combinations are considered. Capacities of residential installations are assumed to be normally distributed around a mean of $7 \mathrm{~kW}$ PV peak power and $7 \mathrm{kWh}$ effective storage capacity with a standard deviation of $2 \mathrm{~kW}$ and $2 \mathrm{kWh}$, and correlated with 0.6. Household load is set fixed at $4.000 \mathrm{kWh}$ / year. Any variance thereof is assumed to be considered in the variability of the installed systems. For commercial clients, typical installation capacities were assumed to be 20 $\mathrm{kW}$ for the PV system and $20 \mathrm{kWh}$ for the storage system with a standard deviation of $5 \mathrm{~kW}$ and $5 \mathrm{kWh}$ and a correlation of 0.6. Annual demand was set at $20.000 \mathrm{kWh}$.

The operation of the storage system is defined as follows. Photovoltaic generation is first matched with local demand. If PV generation exceeds local demand, the battery is charged up to its full capacity. Thereafter, further generation is fed into the grid. If generation from the PV system drops below local demand, the battery is discharged until it is depleted. Further demand is satisfied from the grid. Efficiency losses, maximum power ratings and further technical limitations of the storage system, such as the Depth of Discharge, DOD, were not considered in this study.

According to data made available by the German Federal Network Agency, there are more than 500.000 photovoltaic systems with up to $10 \mathrm{~kW}$ capacity (assumed to be from residential installations) currently installed in Germany. There are also more than 400.000 installations having a capacity between 10-40 kW (assumed to be from commercial installations) [14]. In the forthcoming analysis, we admit there will be a strong increase in PV units as well as in the profitability of storage equipment. We therefore assume a PV capacity addition of $3.5 \mathrm{GW}$ by residential consumers and of 7.6 GW by commercial consumers, and that all these systems are equipped with a storage system.

\section{B. Storage for energy arbitrage}

Arbitrage describes a storage operating strategy, where the storage operator tries to exploit price differentials by taking energy from the grid and storing it, while energy prices are low. Once higher prices prevail, the storage device is discharged back into the grid. As our interest is only the determination of the impact on total electricity demand and not the monetary valuation, it is assumed that energy is taken from the grid to charge the storage device when demand is lowest and fed back to the grid at demand peaks. To consider uncertainty, the timing error of market participants is assumed to be normal distributed around the optimal charging point in time with a standard deviation of one hour.

Maximum combined power generation of pumped storage installations in Germany was $5 \mathrm{GW}$ during the year of 2014 with an average maximum daily generation of $2.8 \mathrm{GW}$ [15]. In our further analysis, we assume the addition of further 5 GW / $10 \mathrm{GWh}$ of capacity, modeled as 1000 storage plants with $5 \mathrm{MW} / 10 \mathrm{MWh}$ each. Besides the maximum power rating, no further technical storage limitations are considered. 


\section{RESULTS}

First, we simulated the residential and commercial consumers using storage for self-consumption and estimated their impact on grid demand. Then, we used storage for arbitrage operations and finally the combined impact of both applications on grid demand is analyzed and discussed.

\section{A. Storage for self-consumption}

Figure 2 shows the electric demand, PV generation and the resulting storage operation for a typical individual commercial consumer over four days. During the morning, PV generation beyond instantaneous demand is first used to charge the battery. Once the battery is full, excess generation is fed into the grid. After sunset, the battery is discharged to supply local demand. Once the battery is depleted, energy is taken from the grid to match demand.

According to the assumptions mentioned in III.A, we estimated the impact of storage installations for selfconsumption on a system level. Figure 3 displays the electricity demand on grid-level, the change in demand due to the PV and storage installations, as well as the remaining grid electricity demand for a four day period.

As demand during the morning hours is satisfied by the PV installations, no energy is taken from the grid and hence electricity demand from the grid drops. Once batteries are fully charged around midday or in the early afternoon, excess PV generation is fed into the network. Demand relative to the initial situation drops even further, as consumers also become producers. During the early evening, grid demand remains lower as consumption is satisfied by battery discharge. Only during the night and early morning hours, once the battery is depleted, grid demand remains unchanged at previous levels.

However, due to the variability of solar radiation, the impact on grid demand of installing a combined PV and storage system varies along the year. For commercial consumers, there are also significant differences between the days of the week. Figure 4 shows the average demand reduction for different system combinations.

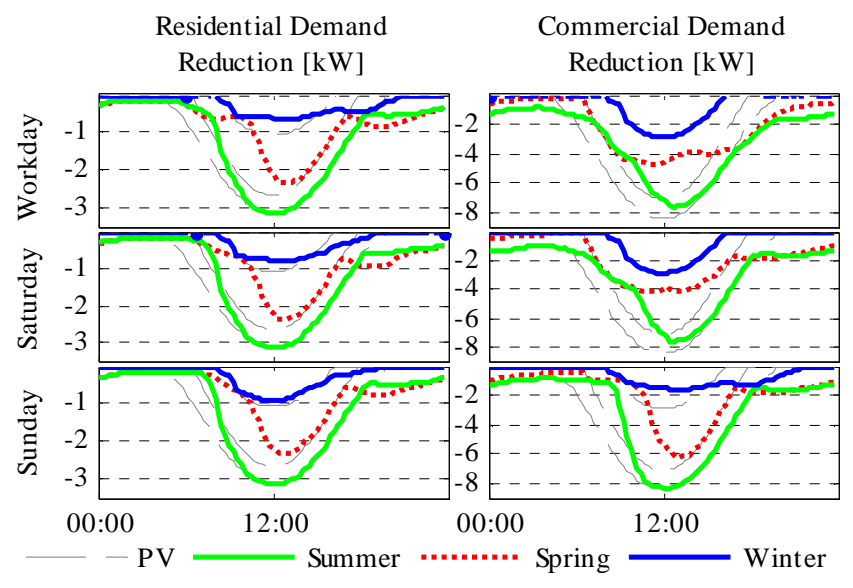

Figure 4: Grid demand reduction for residential and commercial consumers.

As expected, the impact of storage installations is more pronounced on months with high PV generation. The strongest impact is observed by midday and early afternoons in summer time, when excess generation after fully charging the battery is fed into the grid. If the battery was more or less fully charged during the day, demand during early evening remains subdued and the battery is sufficient to match the demand. The lowest impact occurs during the night and in the early morning hours.

These results are also interesting when considering the possibility of combining storage systems with existing PV units. This might be financially attractive in Germany once existing PV units fall out of the subsidized feed-in tariffs. With only a PV system, excess production was immediately fed into the grid. Having a storage system allows storing energy and therefore less energy is injected in the grid while storage is charging. When PV is not sufficient to cover the demand, energy has to be supplied by the storage device and if necessary by the grid. By equipping PV units with a storage device, energy injection to the grid is reduced on sunshine hours, and grid demand is reduced during evening hours.

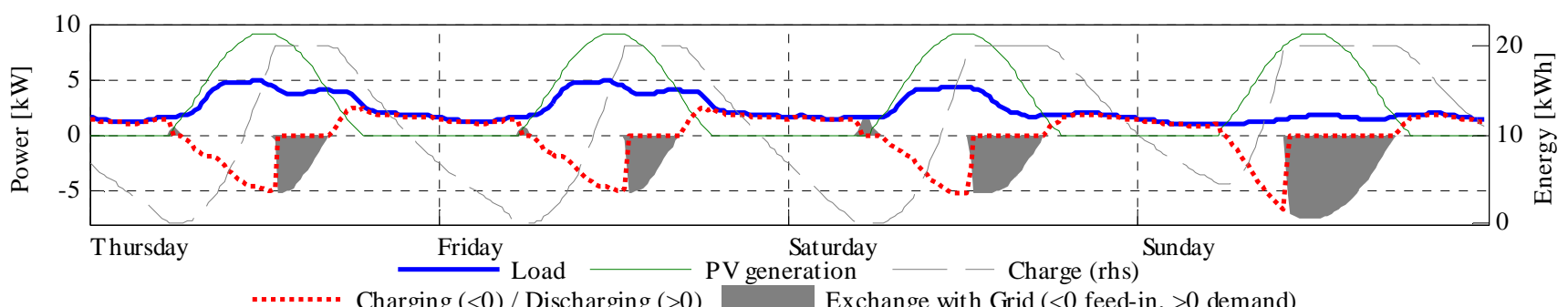

Figure 2: Exemplary electric load, photovoltaic generation and resulting storage operation in spring for a typical commercial consumer

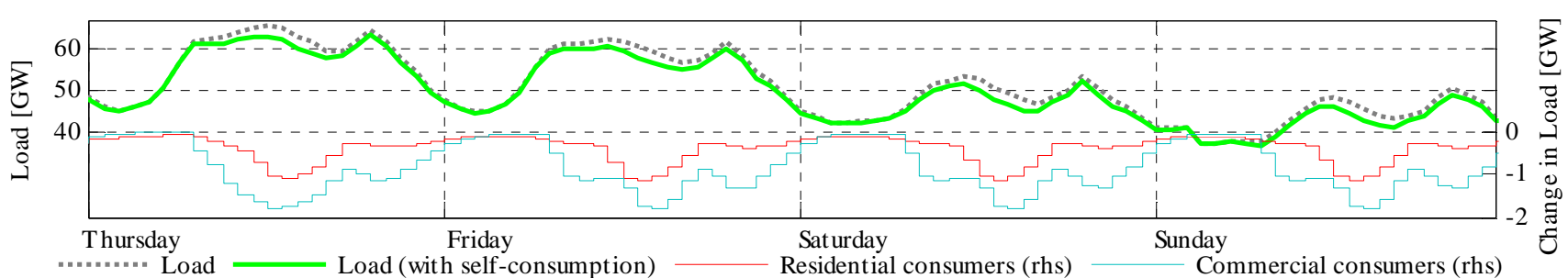

Figure 3: Change in electricity demand from the grid due to self-consumption and feed-in. 


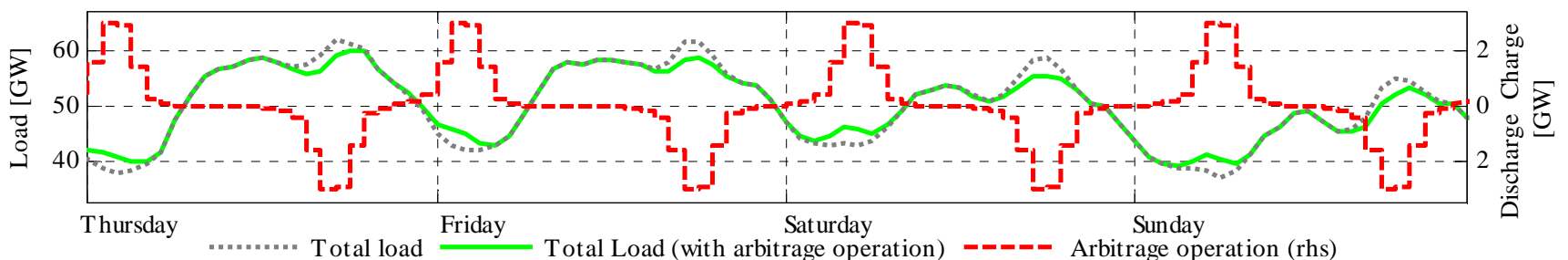

Figure 5: Grid load and storage arbitrage operations over an exemplary four day period.

\section{B. Storage for energy arbitrage}

Figure 5 displays the total electricity demand after the impact of storage installations for self-consumption, the operation of the developed arbitrage algorithm and the resulting remaining load over an illustrative four day period for a total installed capacity of $10 \mathrm{GWh} / 5 \mathrm{GW}$. The storage device is charged during the night, when demand is lower, and thereby the total load is increased during these valley hours. During peak demand hours, this process is reversed and the storage device is discharged. The reduction in peak demand as well as the increase of base load is clearly visible. The effect is identical along the year.

\section{Integrated impact on system level}

The overall impact of the simulated storage operations on the grid demand is shown in Figure 6. From midnight until 5 am, overall electricity demand increases in all cases due to the charging operations of storage installations pursuing arbitrage. This increase is slightly offset by residential and commercial consumers during spring and summer months. In fact, these agents previously took energy from the grid, but are now matching their demand by discharging their battery.

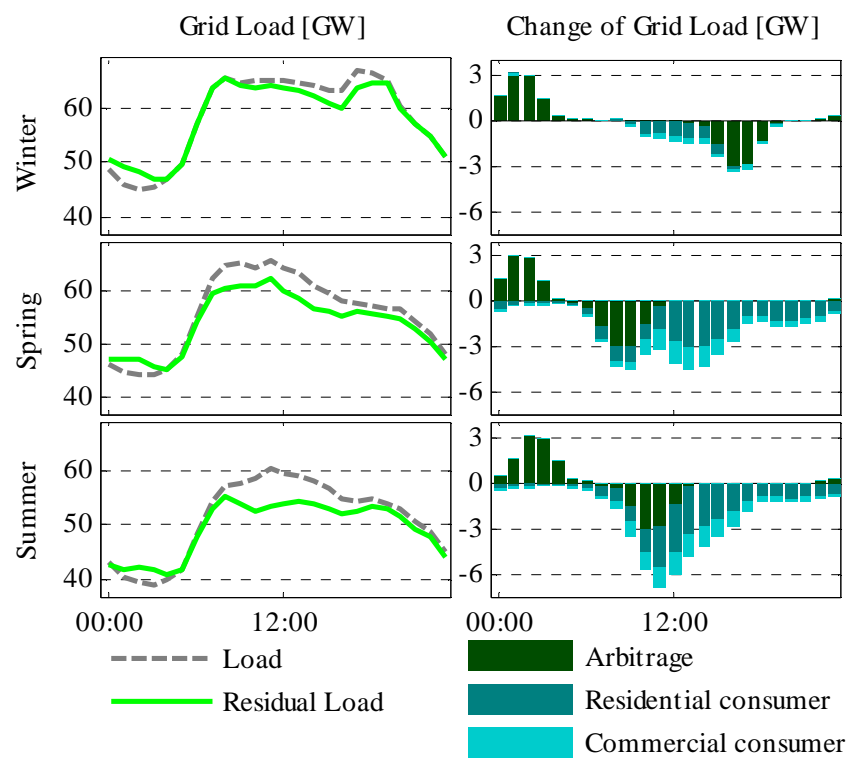

Figure 6: Change in grid load for typical winter, spring and summer days.

During winter months, grid demand remains unchanged until PV generation starts to supply residential and commercial consumers over the late morning and afternoon hours. Storage taking advantage of arbitrage is usually discharged during the evening peak around $6 \mathrm{pm}$. As solar generation during the day was usually not sufficient to fully charge the battery, electricity demand from the grid during the late evening hours is again unchanged.

The impact of storage installations during spring and summer months is different due to the increased availability of PV generation. Arbitrage storage systems are usually discharged during the late morning. Furthermore, electricity demand by residential and commercial consumers is now supplied by local generation instead of the grid, leading to a further demand reduction seen by the grid. Once storage systems for self-consumption are fully charged, excess generation is injected into the grid. Demand during the evening hours and night is matched by the storage device, keeping electricity grid demand at a reduced level.

The most significant impact of the installation of storage systems on grid electricity load is the decrease in peak demand (on average by $5.9 \%$ ), both by arbitrage operations as well as by self-consumption. Whereas storage installations for self-consumption also slightly decrease demand during valley hours, charging for arbitrage operations more than offsets this effect, resulting in an overall demand increase of $3.1 \%$ during valley hours. The range between minimum and maximum load therefore is also reduced, on average by 4.8 GW. The corresponding distribution of occurrences is shown in Figure 7.

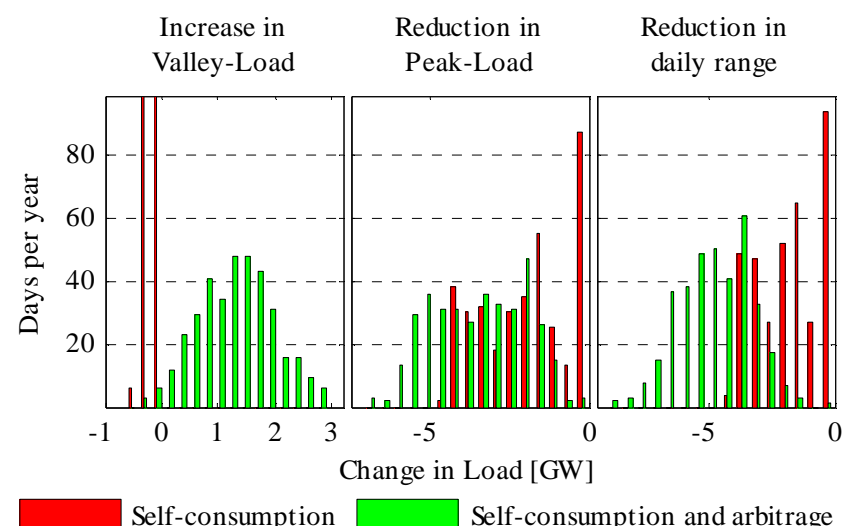

Figure 7: Annual change in Peak- and valley load as well as resulting reduction in daily range.

The resulting load duration curve is depicted in Figure 8 . Each of the graphs in this chart represents the hours per year that the demand exceeds a certain level. The reduction in peak-load hours is obvious. Even though not as significant, valley loads will also occur less frequently. Whereas previously on 2127 hours grid demand exceeded $60 \mathrm{GW}$, this number drops to 1301 hours considering the storage installations admitted in this research. Loads below $40 \mathrm{GW}$ occurred previously during 721 hours. Due to the arbitrage storage operations, this number decreases to 636 hours. 


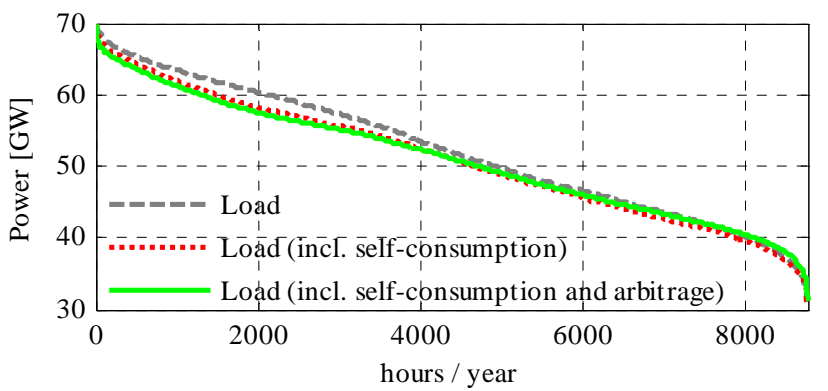

Figure 8: Load duration curves.

\section{CONCLUSIONS AND FUTURE WORK}

In this paper we investigated the potential impact of storage installations on grid demand by developing a model that considers two storage applications (self-consumption and arbitrage) and applying it to realistic load curves. The most relevant findings of this work can be summarized as follows:

- Storage installations for self-consumption reduce peakand valley-demand. While reductions in valley-demand are limited to the previous consumption, reductions on peak-hours are more significant as local surplusgeneration is fed into the grid.

- Arbitrage further reduces peak-demand, but increases valley-demand, more than offsetting the reductions obtained from self-consumption.

- Overall, the load duration curve becomes flatter. Less peak-generation is required, and base-load generation as well as grid-assets will be better utilized.

- Impact on grid-demand by consumers with selfconsumption shows a strong seasonal component due to the variability of PV generation along the year.

- Compared to individual PV units for self-consumption, the injection on the grid of excess generation occurs later and demand during the evening and night remains subdued due to the energy supply of the storage system.

- Market participants pursuing arbitrage operations are not only negatively impacted by further arbitrageurs who reduce the range between valley and peak load, but also by consumers with storage installations, as they reduce the midday/evening peak demand in the grid.

The developed study has a range of limitations, which could be entry points for future research.

- Our analysis assumes smooth demand- and generation curves; in reality, a higher variability is observed influencing demand patterns beyond what we found.

- The developed model assumes several simplifications namely regarding the operation of batteries (for example, no efficiency losses and no DoD limit were used), which should be considered in a more complete analysis.

- A more diverse generation and storage technology mix should be considered, as well as Electric Vehicles.
- Storage operations for self-consumption might be influenced by further objectives such as reducing maximum feed-in power (as for example required by German storage subsidies) or maximum grid-demand.

- The variation of electricity prices along the hours of the day should be internalized in the model as signal for arbitrage operations. Conversely, the impact of grid demand changes on prices should also be evaluated.

\section{ACKNOWLEDGMENT}

The first author would like to thank Fundação para a Ciência e Tecnologia, FCT, that partially funded this research work through the PhD grant no PD/BD/105848/2014.

\section{REFERENCES}

[1] Agora Energiewende, "The Energiewende in the Power Sector: State of Affairs 2014," 2015.

[2] M. Beaudin, H. Zareipour, A. Schellenberglabe, and W. Rosehart, "Energy storage for mitigating the variability of renewable electricity sources: An updated review," Energy Sustain. Dev., vol. 14, no. 4, pp. 302-314, Dec. 2010.

[3] T. Kousksou, P. Bruel, A. Jamil, T. El Rhafiki, and Y. Zeraouli, "Energy storage: Applications and challenges," Sol. Energy Mater. Sol. Cells, vol. 120, pp. 59-80, Jan. 2014.

[4] J. Weniger, T. Tjaden, and V. Quaschning, "Sizing of Residential PV Battery Systems,” Energy Procedia, vol. 46, pp. 78-87, 2014.

[5] J. Hoppmann, J. Volland, T. S. Schmidt, and V. H. Hoffmann, "The economic viability of battery storage for residential solar photovoltaic systems - A review and a simulation model,’ Renew. Sustain. Energy Rev., vol. 39, pp. 1101-1118, Nov. 2014.

[6] L. Dusonchet, M. G. Ippolito, E. Telaretti, G. Zizzo, and G. Graditi, “An optimal operating strategy for combined RES-based generators and electric storage systems for load shifting applications," in 4th International Conference on Power Engineering, Energy and Electrical Drives, 2013, pp. 552-557.

[7] M. Ippolito, M. Di Silvestre, E. Sanseverino, G. Zizzo, and G. Graditi, "Multi-objective optimized management of electrical energy storage systems in an islanded network with renewable energy sources under different design scenarios,” Energy, vol. 64, pp. 648-662, Jan. 2014.

[8] R. Hollinger, B. Wille-Haussmann, T. Erge, J. Sönnichsen, T. Stillahn, and N. Kreifels, "Speicherstudie 2013," 2013.

[9] K. Büdenbender, M. Braun, A. Schmiegel, D. Magnor, and J. C. Marcel, "Improving PV-Integration into the Distribution Grid - Contribution of Multifunctional PV-Battery Systens to stabilised System Operation," in 25th European Photovoltaic Solar Energy Conference and Exhibition, 2010, pp. 4839-4845.

[10]B. Steffen, "Prospects for pumped-hydro storage in Germany," Energy Policy, vol. 45, pp. 420-429, Jun. 2012.

[11]H. Kondziella and T. Bruckner, "Economic analysis of electricity storage applications in the German spot market for 2020 and 2030," in 7th Conference on Energy Economics and Technology, 2012, pp. 1-13.

[12] "Standardlastprofile." [Online]. Available: http://www.kommenergie.de/ unser-netz/standardlastprofil/standardlastprofile-slp.html. [Accessed: 07Dec-2014].

[13] "JRC's Institute for Energy and Transport - PVGIS - European Commission." [Online]. Available: http://re.jrc.ec.europa.eu/pvgis/. [Accessed: 02-Jan-2015].

[14] "Bundesnetzagentur - Datenmeldungen sowie EEG-Vergütungssätze." [Online]. Available: http://www.bundesnetzagentur.de/cln_1411/DE/ Sachgebiete/ElektrizitaetundGas/Unternehmen_Institutionen/Erneuerbar eEnergien/Photovoltaik/DatenMeldgn_EEG-VergSaetze/DatenMeldgn_ EEG-VergSaetze_node.html. [Accessed: 02-Jan-2015].

[15] "Transparency in Energy Markets - Previous day generation.” [Online] Available: http://www.eex-transparency.com/homepage/power/germany /production/usage/previous-day-generation. [Accessed: 12-Jan-2015]. 